\title{
Improvement of Meltdown Temperature of Lithium-Ion Battery Separator using Electrospun Polyethersulfone Membranes
}

\author{
Yang Liu ${ }^{1}$, Hongyang $\mathrm{Ma}^{1,2, *}$, Benjamin S. Hsiao ${ }^{1, *}$, Benjamin $\mathrm{Chu}^{1}$ and Andy H. Tsou ${ }^{3}$ \\ ${ }^{1}$ Department of Chemistry, Stony Brook University, \\ Stony Brook, NY 11794-3400, USA \\ ${ }^{2}$ State Key Laboratory of Organic-Inorganic Composites, Beijing University of Chemical \\ Technology, Beijing 100029, China \\ ${ }^{3}$ Global Chemical Research, ExxonMobil Chemical Company, 5200 Bayway Drive, Baytown, \\ TX 77520, USA
}

\section{Corresponding authors:}

Phone: (631)229-6899 (H.M.); (631)632-7793 (B.S.H). Fax: (631)632-6518

E-mails: mahy@ mail.buct.edu.cn (H.M.); benjamin.hsiao@stonybrook.edu (B.S.H.) 


\begin{abstract}
Polyethersulfone (PES) electrospun nanofibrous membranes have been prepared and deposited on both sides of a microporous polyethylene (PE) substrate to fabricate a nanocomposite separator, which exhibits a high meltdown temperature (MDT) to prevent the thermal runaway within the battery under the condition of overcharging or abuse. To improve adhesion to electrospun PES nanofibrous membranes, the PE substrate with low surface energy and hydrophobic nature was etched with chromic acid and characterized with atomic force microscopy (AFM) and infrared spectroscopy (FTIR) techniques as well as the water contact angle test. Compared to the original film, the modified PE substrate showed a nearly 10-times increase in adhesive strength to the electrospun PES membrane. The morphology of the electrospun PES membrane, controlled by different electrospinning flow rates, was also demonstrated to have a substantial impact on adhesion, where a 5-fold increase of the adhesive strength was observed when the flow rate increased from $20 \mu \mathrm{L} / \mathrm{min}$ to $60 \mu \mathrm{L} / \mathrm{min}$. The composite PES/PE/PES separator, structured as a PE substrate sandwiched in 2 electrospun PES membranes, maintained the low shutdown temperature (SDT) of $131^{\circ} \mathrm{C}$ but achieved a significantly higher MDT of $221^{\circ} \mathrm{C}$. Furthermore, the high porosity of the electrospun PES membrane ensured that the air permeability of the separator was not sacrificed when compared with the original PE separator.
\end{abstract}

\title{
Keyword
}

Battery separator, polyethylene, electrospun polyethersulfone membrane 


\section{Introduction}

Lithium-ion batteries (LIBs), owing to their advantages, such as better self-discharge performance, longer cycle life, higher energy density, and higher operational voltage over the NiCd and NiMH systems [1], have been used in over $90 \%$ of cell phones, laptops, camcorders, and many hybrid electric vehicles (HEVs) and electric vehicles (EVs) [2-6]. A lithium-ion battery consists of a metal oxide (e.g., $\mathrm{LiCoO}_{2}$ ) positive electrode and a graphite negative electrode where a porous separator film is placed between the 2 electrodes and is immersed in the ionically conductive electrolyte [7-9]. The separator film plays an important role in the lithium-ion battery, which allows the ionic flow and keeps the positive and negative electrodes apart to prevent short circuits within the battery. The pore size of the film in the submicron range $(<1 \mu \mathrm{m})$ has been shown to be small enough to prevent dentritic lithium going through $[5,10]$.

A microporous polyethylene (PE) separator film, due to its low melting point at around $135^{\circ} \mathrm{C}$, provides a safety feature to prevent thermal runaway reactions in the battery. When the cell temperature reaches the shutdown temperature, slightly lower than the melting point of PE, the separator works as a thermal fuse by shutting down the pores and thus prevents ionic transport and cell reaction. However, if the temperature is further elevated above the melting point of the separator, the separator is highly likely to undergo a complete meltdown and lose its mechanical integrity, which results in the contact of the electrodes and direct chemical reaction, leading to severe damage to the battery [11-13]. An ideal separator should possess a low SDT and a high MDT, and therefore could provide a greater safety margin to the battery. To enhance the MDT of the PE separator, Celgard, LLC developed the PP/PE bi-layers and PP/PE/PP tri- 
layers combing the low melting temperature of $\mathrm{PE}$ and the high melting temperature of polypropylene (PP), with the MDT being increased to around $180^{\circ} \mathrm{C}$ [14]. Chung et al. conducted the PE substrate coating with various amounts of ethylene glycol dimethacrylate (DEGDMA) by radical polymerization in ethanol solution. The MDT of the coated PE separator was increased to $155^{\circ} \mathrm{C}$ [15]. They also coated the PE substrate with nanocomposites composed of DEGDMA polymer and silica nanoparticles, which increased the MDT to $170^{\circ} \mathrm{C}$. However, this coating approach decreased the porosity of the membrane and therefore reduced the battery performance [16]. Electrospun nanofibrous membrane with high porosity of $70 \% \sim 80 \%$, and adjustable pore size falling in the range of microns and submicrons $[17,18]$, has also been demonstrated to be capable for use as a LIB separator; however, the electrospun membrane does not provide the shutdown feature $[19,20]$. It should be ideal to make a composite membrane, which combines the advantages of the PE separator (i.e., shutdown feature) and the electrospun membrane.

PES is the material that exhibited great chemical and mechanical stability and, more importantly, excellent heat resistance (with a $\mathrm{T}_{\mathrm{g}} \sim 220^{\circ} \mathrm{C}$ based on different sources) [21,22]. Unfortunately, the adhesion of PE to other materials is usually poor due to its low surface tension (30-31 dynes/cm), hydrophobic, and chemically inert properties [23,24]. Both physical and chemical methods can be used to improve surface adhesion. The physical method generally involves mechanical abrasion to generate more surface roughness, therefore enhancing mechanical interlocking with the adhesive $[25,26]$. Meanwhile, a wide variety of surface chemical modification methods such as chemical etching [27-31], flame treatment [32], plasma 
treatment [29], and UV exposure [33] have also been reported to introduce polar functional groups onto the surface and to increase the surface tension.

In this work, a nanocomposite separator film was prepared by depositing the electrospun PES membrane directly on both sides of a porous PE substrate, resulting in a sandwiched structure. A chemical modification method using chromic acid was applied on PE substrate, with the modification degree controlled by the acid treatment time, to improve the adhesive strength between PE and PES. The adhesion was also optimized by controlling the morphology of the electrospun PES membranes through the feeding rate of polymer solution during the electrospinning process. It was expected that the meltdown temperature would be greatly improved above that of the commercial PP/PE/PP film, while the new sandwiched structure could still keep the low shutdown temperature of the PE substrate. Also, due to the high porosity of the electrospun PES membrane, the porosity of the PE substrate was not likely to be reduced and the performance of the separator would not be sacrificed. The preliminary tests on the separator film properties of the PES/PE/PES composite membrane were carried out at Exxon Mobil Chemical Corp.

\section{Experimental}

\subsection{Materials}

Poly(ethersulfone) (PES) with a weight-average molecular weight $\left(\mathrm{M}_{\mathrm{w}}\right)$ of $63,000 \mathrm{~g} / \mathrm{mol}$ was purchased from Solvay Advanced Polymers. Dimethylformamide (DMF, 99.9\%), potassium 
dichromate, and sulfuric acid (95.0 - 98.0\%) were purchased from Sigma Aldrich. PES powder was dried in vacuum at $120^{\circ} \mathrm{C}$ for 6 hours, and DMF was dried over molecular sieve $(3 \AA)$ before use. The polyethylene lithium ion separator film (E25MMS) with an average thickness of $25 \mu \mathrm{m}$ was provided by the Exxon Mobil Chemical Corp.

\subsection{Preparation of electrospinning solution}

A certain amount of PES powder was dissolved in the solvent of DMF and the solution was stirred at $90{ }^{\circ} \mathrm{C}$ for 2 days to make the electrospinning solution with the concentration of 28 wt $\%[34,35]$.

\subsection{PE substrate treatment}

The polyethylene lithium ion separator film (E25MMS) was chosen as the base substrate. This PE substrate was first immersed in ethanol followed by washing with de-ionic (DI) water several times to remove surface contaminants. The chromic acid solution was prepared based on the literature [31], where a weight ratio of $\mathrm{K}_{2} \mathrm{CrO}_{7}: \mathrm{H}_{2} \mathrm{O}: \mathrm{H}_{2} \mathrm{SO}_{4}=7: 12: 150$ was employed. The PE substrate was immersed in the chromic acid solution at room temperature for $0 \mathrm{~s}, 10 \mathrm{~s}, 30 \mathrm{~s}, 60 \mathrm{~s}$, $120 \mathrm{~s}$, and $240 \mathrm{~s}$, respectively; then, it was washed in running distilled water overnight and dried in vacuum before use.

\subsection{Electrospinning of PES membrane}


A typical custom-built electrospinning setup was used to fabricate PES nanofibrous membrane. The detailed description of the equipment can be found in the literature [18]. The treated PE substrate with chromic acid solution was taped on the aluminum foil wrapped on a rotating drum (diameter: $10 \mathrm{~cm}$, rotating speed: $300 \mathrm{rpm}$ ), and the spinneret-to-collector distance was set at $10.5 \mathrm{~cm}$ with the applied voltage of $12 \mathrm{kV}$. A stepping motor was used to control the oscillatory translational motion of the spinneret in order to achieve the electrospun membrane with uniform thickness. Different flow rates of PES polymer solution, $20 \mu \mathrm{L} / \mathrm{min}, 40 \mu \mathrm{L} / \mathrm{min}, 60$ $\mu \mathrm{L} / \mathrm{min}$, and $80 \mu \mathrm{L} / \mathrm{min}$ were employed in the electrospinning process. The electrospinning performance was operated in a closed chamber, with a temperature of $26 \pm 1^{\circ} \mathrm{C}$ and a relative humidity of $40 \pm 2 \%$ monitored by a temperature and humidity meter (catalog number: 11-66119, Fisher Scientific).

\subsection{Characterizations of the chemically treated PE surface}

The surface topology of the PE substrates before and after treatment was characterized using an atomic force microscope (AFM) (Dimension 3000, VEECO, Plainview, NY) equipped with version 5.12r5 NanoScope III Software. The chemical change of the surface produced by the chromic acid etching was characterized using Fourier transform infrared spectroscopy (FTIR) with attenuated total reflectance (ATR) accessory (Nicolet iS10 spectrophotometer, Thermo Scientific, Inc.). Each sample was scanned 16 times in the wavenumber range of $4000-650 \mathrm{~cm}^{-1}$. The surface hydrophobicity was determined with a water contact angle goniometry (CAM200 Optical Contact Angle Meter, KSV Instruments, Ltd.), where $10 \mu \mathrm{L}$ of Milli-Q water was used as a probe liquid and three different spots were tested for each sample. 


\subsection{Characterizations of electrospun PES membrane and adhesion strength measurements}

The electrospun PES membrane was deposited on one side of the treated PE substrate

only in the following tests. Scanning electron microscopy (SEM, LEO 1550) was employed to observe the morphology of the electrospun PES membrane after platinum-sputter coating, where the average nanofiber diameter and standard deviation can be figured out using Leica software (http://dell.chem.sunysb.edu). By measuring the total thickness of the PES/PE membrane with a digital micrometer, the thickness of the PES electrospun layer can be calculated by the difference of the total PES/PE membrane and that of the PE substrate. The porosity of the PES electrospun layer was calculated based on the gravimetric method [36], where the PES bulk density of 1.37 $\mathrm{g} / \mathrm{cm}^{3}$ has been used.

The adhesion strength of the PES electrospun layer to the PE substrate was determined by peeling off the PES electrospun layer from the PE substrate [34]. Typically, a piece of doublefaced adhesive tape $(10 \mathrm{~mm} \times 5 \mathrm{~mm})$ was used to affix the PE side of the PE/PES membrane to the bench, and with another face of the tape affix the PES electrospun layer of the PE/PES membrane $(10 \mathrm{~mm} \times 5 \mathrm{~mm})$ to a loading fixture hooked with a Dillon BFG-50N force gauge. A load was gradually applied $90^{\circ}$-upwards until the PES membrane was pulled off the PE substrate. The maximum force to pull the PES electrospun layer off was recorded, and the adhesion strength was calculated by the maximum force divided by the membrane area $(10 \mathrm{~mm} \times 5 \mathrm{~mm}$ in this case). 


\subsection{Battery performance tests on the PES/PE/PES nanocomposite membrane}

The electrospun PES electrospun nanofibrous layer was deposited on both sides of the treated PE substrate in the following tests, and the properties of the PES/PE/PES nanocomposite separator were tested as follows.

In a SDT measurement, the separator was latched in a cell, where the electrical impedance was measured as a function of temperature. The temperature was recorded as the shutdown temperature when a sharp impedance increase was observed. The MDT is a measurement of a separator's ability to hold its mechanical integrity and to provide the safety margin above the SDT. Thermal mechanical analysis (TMA) was employed to determine the MDT, where the separator was held under a constant load and the degree of elongation versus temperature was investigated. The temperature was recorded as the MDT when the elongation of the separator dramatically increased, meaning that the separator lost its mechanical integrity.

More than SDT and MDT, Gurley number was determined by following the method ASTM-D726 (B). It is a measurement of air permeability of the membrane, expressed by the time required for a specific amount of air passing through a specific area of the membrane under a certain pressure. For LIB separators, the permeability of the separator is usually reflected by air permeability. The Gurley number is also a good estimation of the electrical resistance (ER) of the membrane, as it is proportional to the ER for a certain membrane morphology [5]. 
Puncture strength (PS) is to measure the physical strength of the separator film that can bear in cell assembly and other daily use, since the separator is in direct touch with the rough surfaces of the two electrodes. PS of the chosen membrane was characterized as the load that applied for a needle to pierce the separator sample [37].

\section{Results and Discussion}

3.1 Morphology, surface chemistry, and surface hydrophobicity of chemically treated PE substrate

It is well-known that chemical etching using strong oxidation acid, such as concentrated sulfuric acid, nitric acid and chromic acid, can induce physical and chemical changes to the material surface, which could be identified with AFM, as shown in Figure 1.
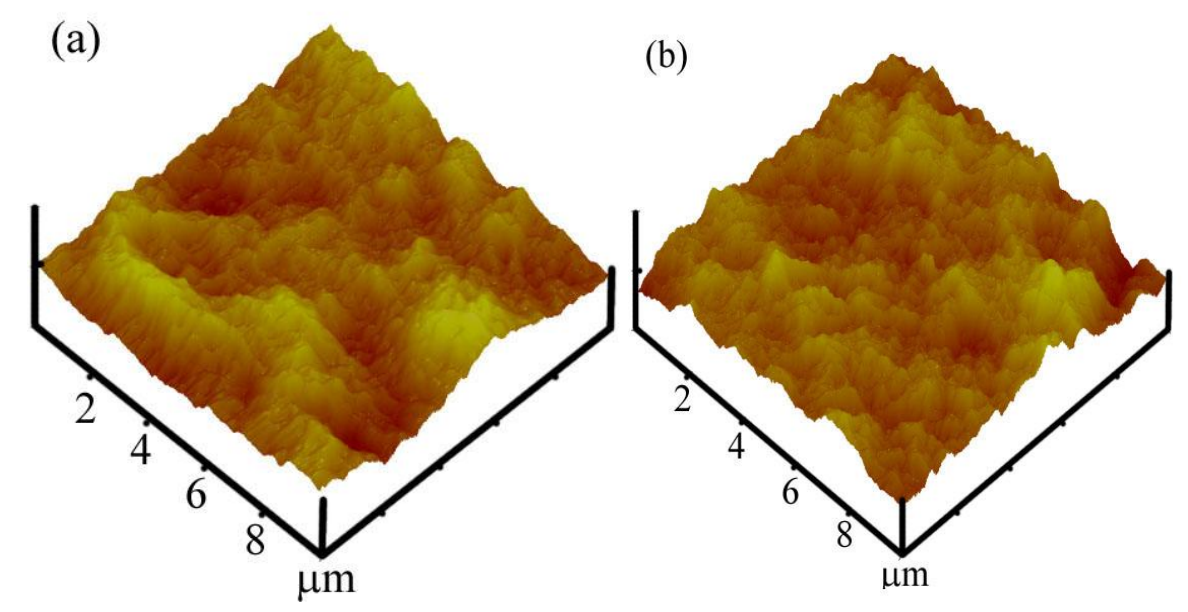

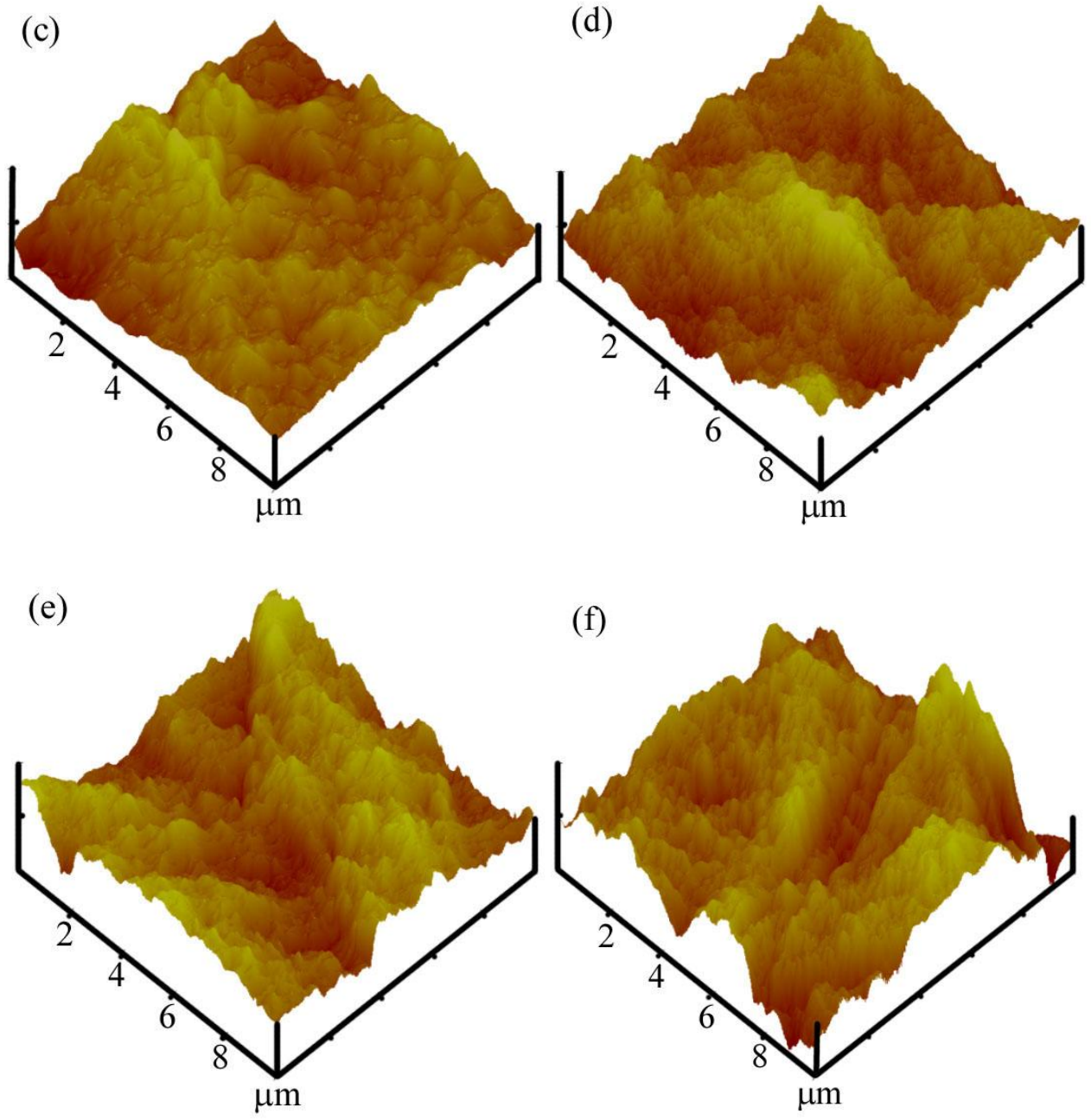

Figure 1 AFM images of PE substrate treated with chromic acid for (a) $0 \mathrm{~s}$; (b) $10 \mathrm{~s}$; (c) $30 \mathrm{~s}$; (d) $60 \mathrm{~s}$; (d) $120 \mathrm{~s}$; and (e) $240 \mathrm{~s}$. Scale of x axis: $2.0 \mu \mathrm{m} / \mathrm{div}$; $\mathrm{z}$ axis: $200 \mathrm{~nm} / \mathrm{div}$.

This figure shows the 3D surface topography of untreated PE and that of treated with different acid-treatment time, observed using AFM with an area of $10 \times 10 \mu \mathrm{m}^{2}$. Both qualitative and quantitative roughness study of the surface morphology and topology in the nano-scale range could be performed with AFM. The $\mathrm{R}_{\mathrm{rms}}$ (root mean squared) value of the untreated PE substrate was $29.9 \mathrm{~nm}$. The $\mathrm{Z}$ range, being the maximum height difference between the peaks and valleys, 
was $201.7 \mathrm{~nm}$. From the 3D representation of the samples, it could be seen that the surface roughness was increased with the acid-treatment time, which was also confirmed by the quantitative measurements of the $\mathrm{R}_{\mathrm{rms}}$ and $\mathrm{Z}$ range value, as listed in Table 1 .

Table 1 Variation of root mean squared surface roughness $R_{r m s}$ and $Z$ range obtained from Atomic Force Microscopy analysis with respect to different acid-treatment time.

\begin{tabular}{ccc}
\hline Acid treated time $(\mathrm{s})$ & $\mathrm{R}_{\mathrm{rms}}(\mathrm{nm})$ & Z range $(\mathrm{nm})$ \\
\hline 0 & 29.9 & 201.7 \\
10 & 31.0 & 250.7 \\
60 & 41.0 & 293.1 \\
120 & 45.5 & 336.4 \\
240 & 53.3 & 349.1 \\
\hline
\end{tabular}

Both $\mathrm{R}_{\mathrm{rms}}$ and $\mathrm{Z}$ range values were increased with the acid treatment time. Specifically, with the chromic acid treated for $240 \mathrm{~s}$, the $\mathrm{R}_{\mathrm{rms}}$ of the PE substrate surface was increased to 56.3 $\mathrm{nm}$, and the $\mathrm{Z}$ range was increased to $423.8 \mathrm{~nm}$, representing a remarkable increase in surface roughness.

The chemical change of the PE substrate surface was evaluated by FTIR, as shown in Figure 2 . 


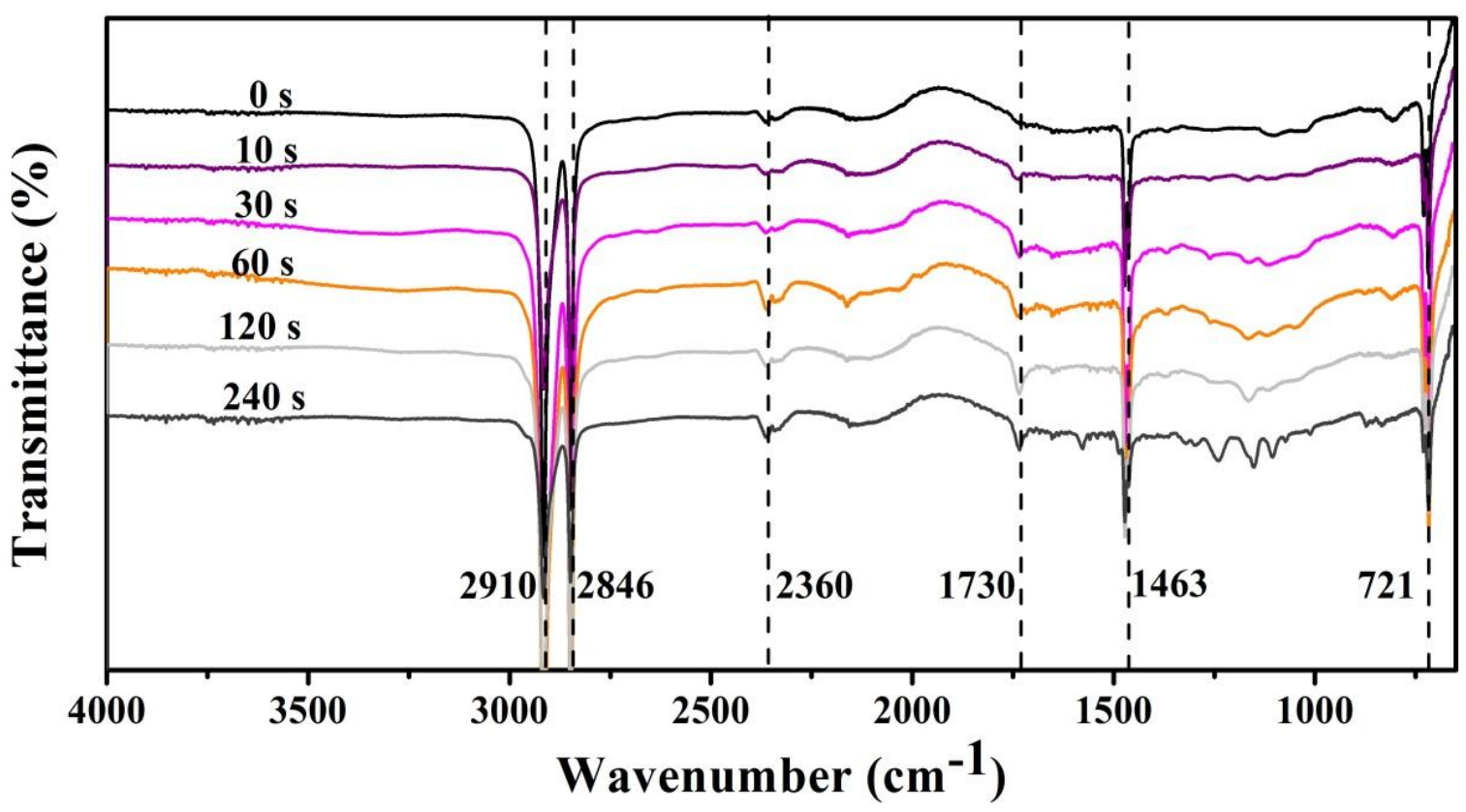

Figure 2 FTIR spectra of PE substrate surface with different chromic acid-treatment times.

The peaks at $2910,2846,1463$, and $721 \mathrm{~cm}^{-1}$ in the spectra corresponded to the $\mathrm{CH}_{2}$ asymmetric stretching, symmetric stretching, bonding deformation, and rocking deformation of polyethylene, respectively [38]. Compared to the untreated surface, the presence of the adsorption peak at $1730 \mathrm{~cm}^{-1}$ indicated the existence of $\mathrm{C}=\mathrm{O}$ functional group, which was introduced by the chromic acid treatment. The strengthening peak signal with treatment time also indicated more polar groups were created on the surface with the acid-treatment time. It was also noted that for the PE substrate treated with chromic acid for 120 and 240 seconds, multiple peaks in the range of 1000-1300 $\mathrm{cm}^{-1}$ appeared, revealing the generation of C-O groups. The absorption peak at $2360 \mathrm{~cm}^{-1}$ for all samples is due to the atmospheric $\mathrm{CO}_{2}[39]$. 
The introduction of polar groups was believed to have increased surface tension, and this could be validated by the water contact angle test.

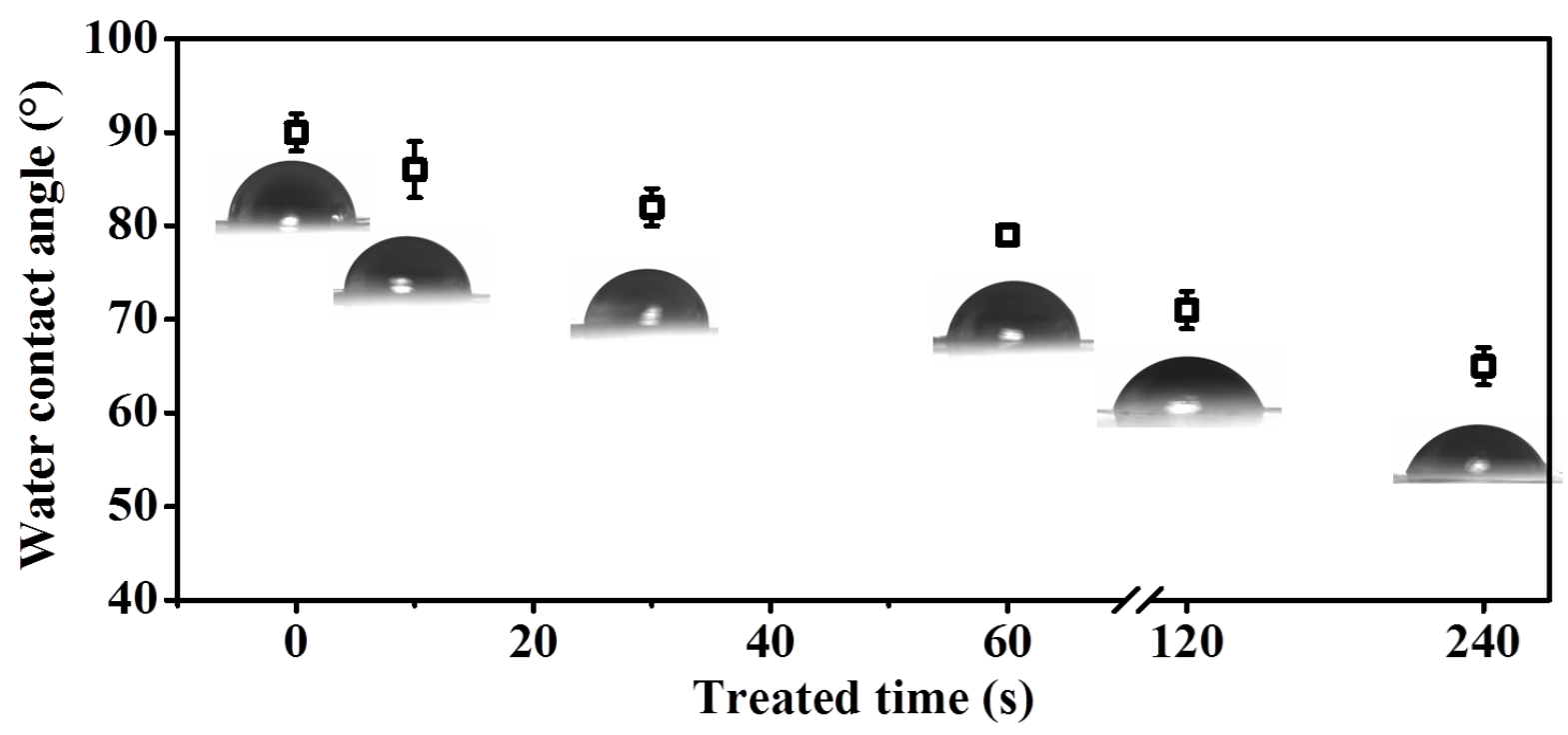

Figure 3 Water contact angles of PE separator films treated with chromic acid for different time periods.

The untreated PE substrate had a water contact angle of $89 \pm 2^{\circ}$, indicating its hydrophobic nature. With the chromic acid treatment and prolongation of treatment time, the water contact angle was gradually decreased to $86 \pm 3^{\circ}, 82 \pm 2^{\circ}, 79 \pm 1^{\circ}, 71 \pm 2^{\circ}, 65 \pm 2^{\circ}$ at $10 \mathrm{~s}$, 30 s, 60 s, 120 s, 240 s, respectively (Figure 3). The decrease in the water contact angle could be a result of the introduction of more functional groups, resulting in higher surface tension increased with longer acid-treatment time.

Another factor, surface roughness, was also considered as contributing to the decrease in the water contact angle. Based on Young's equation,

$$
\cos \theta=\frac{\gamma_{S G}-\gamma_{S L}}{\gamma_{L G}}
$$


where $\theta$ is the water contact angle, and $\gamma_{\mathrm{SG}}, \gamma_{\mathrm{LG}}, \gamma_{\mathrm{SL}}$ are the interfacial surface tensions between the solid and the vapor, the liquid and the vapor, and the solid and the liquid, respectively.

When dealing with the water contact angle on a rough surface, based on the Wenzel model, a roughness factor must be included and can be adequately expressed by [40]

$$
f=\frac{A}{A_{0}}
$$

where $\mathrm{A}$ is the "real" total surface area, and $\mathrm{A}_{0}$ is the apparent surface area. Derived from Young's equation, the Wenzel model can be expressed as

$$
\cos \theta^{*}=f \cos \theta
$$

where $\theta^{*}$ is the apparent water contact angle.

As the water contact angles of the PE substrates fell in the range of $0 \sim 90^{\circ}$, a longer acid etch time increased the surface roughness factor (as $f>1$ ) to a larger extent and therefore can result in a smaller water contact angle based on equation (3).

\subsection{Adhesion strength of electrospun PES layer to the PE substrates}

The effect of chromic acid treatment of the PE substrate on adhesion has been studied, and the corresponding change of the adhesion strengths is shown in Figure 4. 


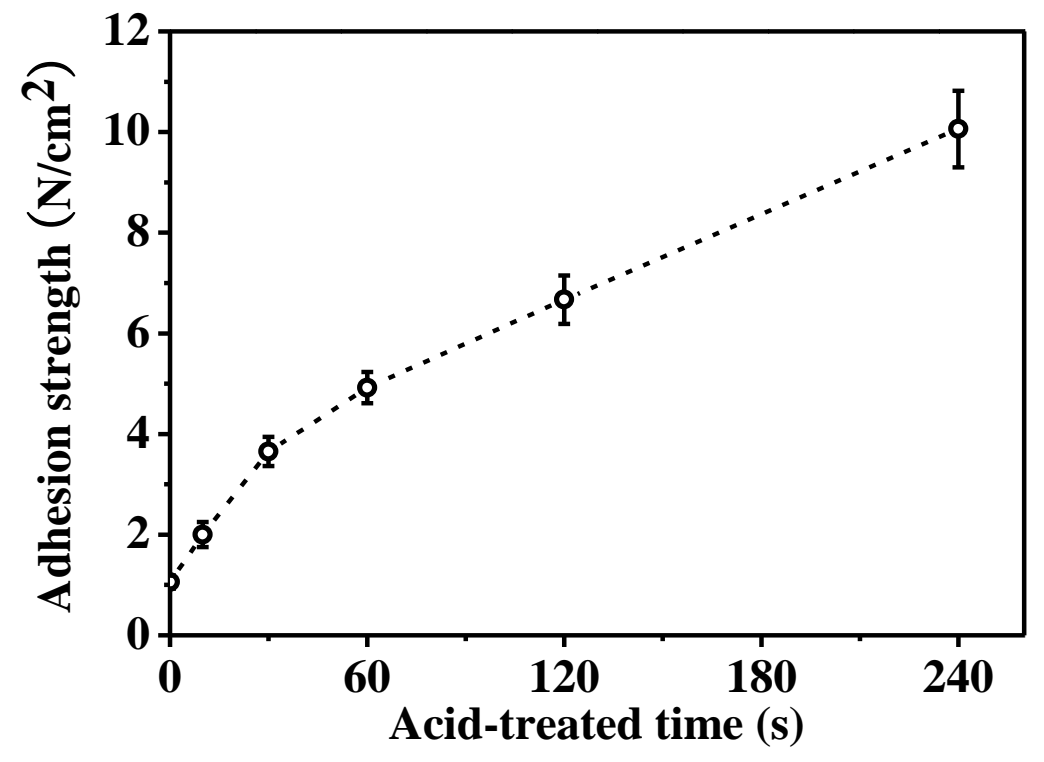

Figure 4 Effect of chromic acid treatment time of PE substrates on adhesion between PES membrane (electrospun at a flow rate of $60 \mu \mathrm{L} / \mathrm{min}$ ) and PE substrate.

The adhesion strength of the electrospun nanofibrous layer prepared at a flow rate of 60 $\mu \mathrm{L} / \mathrm{min}$ to the original PE substrate was $1.06 \pm 0.13 \mathrm{~N} / \mathrm{cm}^{2}$. When the PE substrate was treated with chromic acid, the adhesion strength of the electrospun membrane increased with increasing acid-etching time due to the increase in the surface tension and roughness of the PE substrates. The PE substrate treated with chromic acid for $240 \mathrm{~s}$ showed an adhesion strength of $10.06 \pm$ $0.76 \mathrm{~N} / \mathrm{cm}^{2}$ to the electrospun PES membrane, indicating a significant improvement of adhesion strength ( 10 times) brought by the chromic acid treatment.

The morphology of the electrospun PES membrane, dominating its available contact area to the PE separator film, could also affect the adhesion strength. It is known that the morphology 
of the membrane and the state of fibers can be manipulated by using different electrospinning parameters. Figure 5 shows the adhesion strength change with respect to the electrospinning flow rate, with the PE substrate having been treated with chromic acid for $240 \mathrm{~s}$.

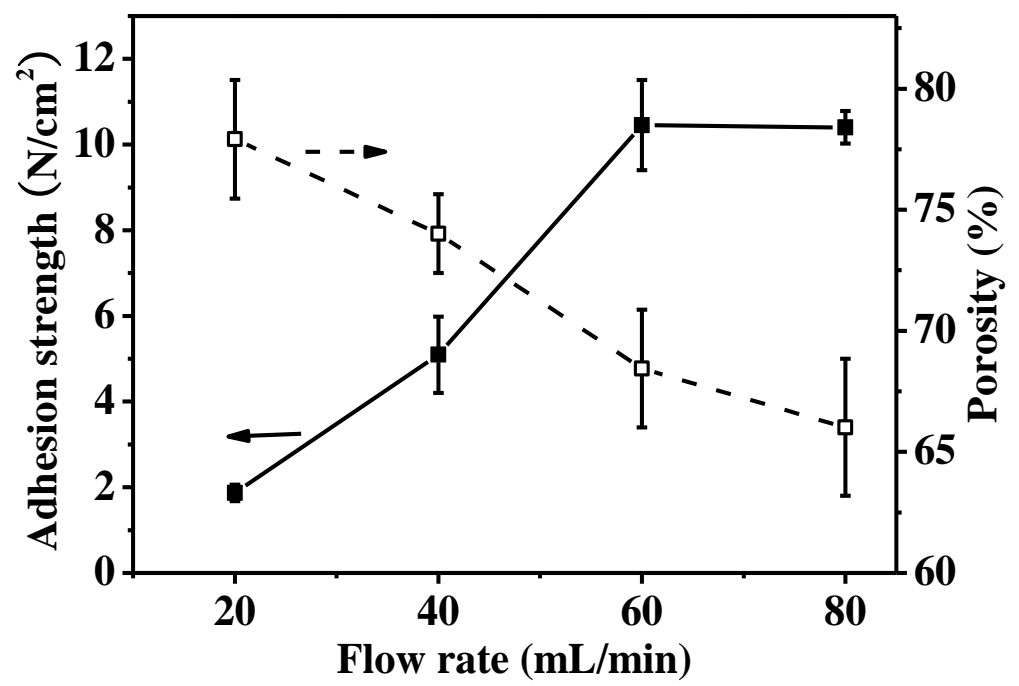

Figure 5 Effect of electrospinning flow rate on the adhesion of PE substrate to the electrospun PES membrane and the porosity of the electrospun PES membrane, with the PE substrate having been treated with chromic acid for $240 \mathrm{~s}$.

At a low flow rate of $20 \mu \mathrm{L} / \mathrm{min}$, the adhesion strength was $1.87 \pm 0.19 \mathrm{~N} / \mathrm{cm}^{2}$. As the flow rate increased to $40 \mu \mathrm{L} / \mathrm{min}$ and $60 \mu \mathrm{L} / \mathrm{min}$, the adhesion strength increased to $5.09 \pm 0.89$ $\mathrm{N} / \mathrm{cm}^{2}$ and $10.45 \pm 1.05 \mathrm{~N} / \mathrm{cm}^{2}$, respectively. A further increase in the flow rate to $80 \mu \mathrm{L} / \mathrm{min}$ resulted in a comparable adhesion strength of $10.40 \pm 0.38 \mathrm{~N} / \mathrm{cm}^{2}$ to that at $60 \mu \mathrm{L} / \mathrm{min}$. Therefore, the states of the nanofibers, i.e., whether they are dry or wet when deposited onto the PE separator film, also have a great influence on the adhesion [20]. By varying the flow rate during electrospinning process, an over 5-fold increase in the bonding strength between the electrospun PES layer and the PE substrate was achieved. 
It should be noted that a high porosity of the separator in LIBs has been required for charges transportation, where a lower porosity of electrospun PES nanofibrous layer than that of the PE substrate could decrease the performance of the separator. In reality, due to the interconnected pore structure of the electrospun membrane, the porosity reached a high value of $77.9 \pm 2.5 \%$ at the electrospun flow rate of $20 \mu \mathrm{L} / \mathrm{min}$. With increasing flow rate from $40 \mu \mathrm{L} / \mathrm{min}$ to $80 \mu \mathrm{L} / \mathrm{min}$, the porosity was gradually decreased correspondingly from $74.0 \pm 1.6 \%$ to $66.0 \pm$ 2.8\%. Fortunately, despite the decreased porosity of the electrospun PE membrane with the electrospun flow rate, e.g., $68.4 \pm 2.4 \%$ at electrospun flow rate of $60 \mu \mathrm{L} / \mathrm{min}$, it still maintained a higher value than that of the PE substrate $(\sim 40 \%$ [5]). As a result, the total porosity of PES-PE nanocomposite separator was increased, which will be of benefit to the separator for ion transportation. The effect of surface morphologies of electrospun PES nanofibrous membranes on adhesion strength has also been investigated from SEM images of the membranes electrospun at different flow rates.
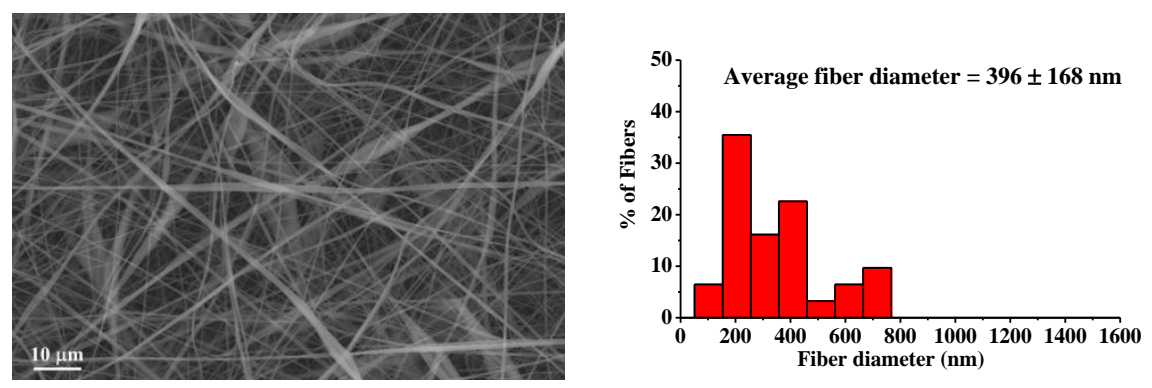

(a)
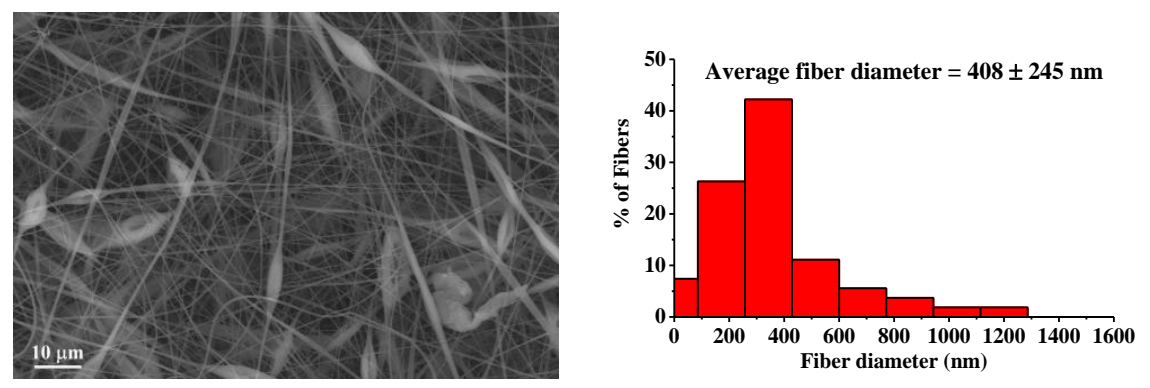
(b)
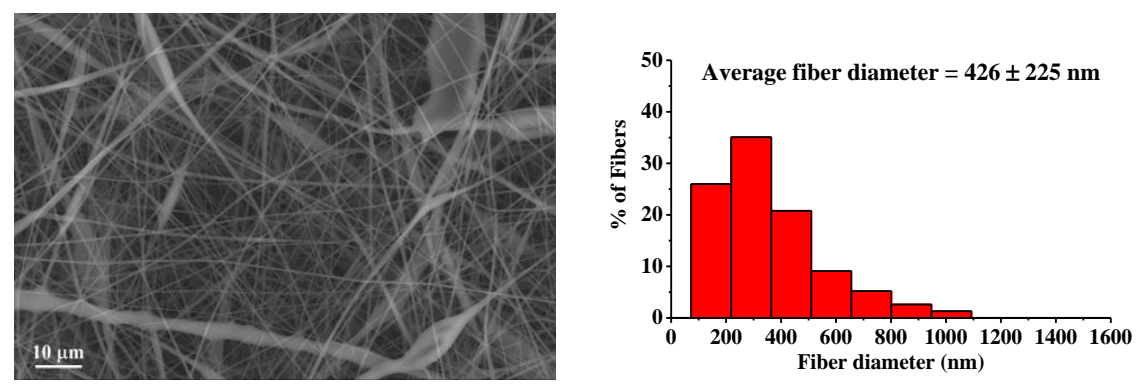

(c)
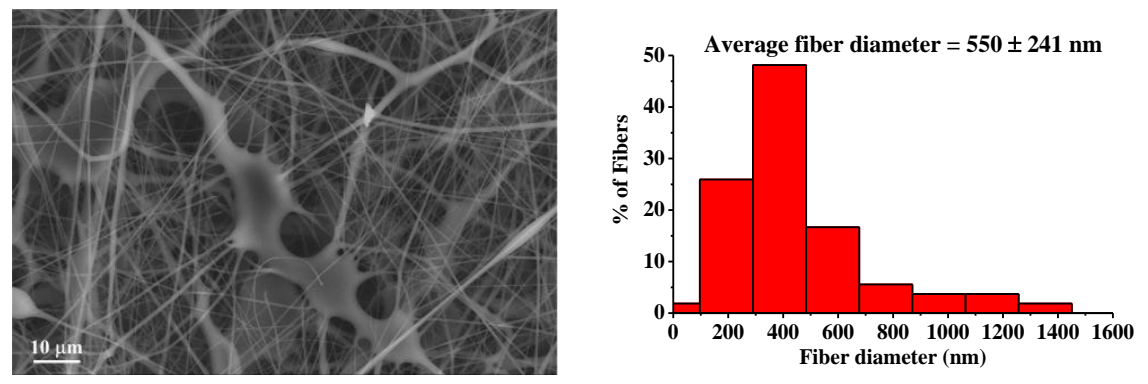

(d)

Figure 6 SEM images and fiber diameter distribution of electrospun PES membranes at the flow rate of (a) $20 \mu \mathrm{L} / \mathrm{min}$; (b) $40 \mu \mathrm{L} / \mathrm{min}$; (c) $60 \mu \mathrm{L} / \mathrm{min}$; (d) $80 \mu \mathrm{L} / \mathrm{min}$.

As shown in Figure 6, the average fiber diameter increased and the fiber diameter distribution became broadened with the increasing flow rate. The average fiber diameter electrospun at flow rates of $20 \mu \mathrm{L} / \mathrm{min}, 40 \mu \mathrm{L} / \mathrm{min}, 60 \mu \mathrm{L} / \mathrm{min}$, and $80 \mu \mathrm{L} / \mathrm{min}$ ranged from $396 \pm$ $168 \mathrm{~nm}, 408 \pm 245 \mathrm{~nm}, 426 \pm 225 \mathrm{~nm}$, to $550 \pm 241 \mathrm{~nm}$, respectively. This could be because a greater volume of solution was drawn away from the needle tip when higher flow rate applied [18]. In terms of fiber morphology, at the low flow rate of $20 \mu \mathrm{L} / \mathrm{min}$, the membrane structure was dominated with nanofibers. As the flow rate was increased to $40 \mu \mathrm{L} / \mathrm{min}$, a mixed structure of nanofibers and a greater amount of spindle-shaped fibers was formed. When the flow rate was further increased to $60 \mu \mathrm{L} / \mathrm{min}$ and $80 \mu \mathrm{L} / \mathrm{min}$, the feeding rate of solution to the spinneret was in excess to the rate of the solution that could be drawn from the spinneret, and the polymer 
solution dripped onto the membrane. The morphology change of the membrane from the nanofiber to the spindle and solution dripping was believed to enhance the adhesion between the electrospun membrane and the PE substrate. However, the effect of the morphology change on the electrospun membrane porosity was also obvious. More beads or dripping resulted in less membrane porosity, which was confirmed by the porosity measurement.

\subsection{Preliminary battery performance of PES/PE/PES nanocomposite separator}

Some basic properties of the original PE substrate, the PES/PE/PES nanocomposite membrane, and a Celgard 2320 film were listed in Table 2.

Table 2 Properties of different lithium-ion battery separators

\begin{tabular}{cccc}
\hline & E25MMS & Composite & Celgard 2320 \\
& (Original film) & membrane & (Commercial film) \\
\hline Composition & PE & PES/PE/PES & PP/PE/PP \\
Thickness $(\mu \mathrm{m})$ & 25 & $43 \pm 2$ & 20 \\
Porosity $(\%)$ & 36 & $36^{1}$ & 39 \\
SD temperature $\left({ }^{\circ} \mathrm{C}\right)$ & 131 & $\sim 49^{2}$ & 139 \\
MD temperature $\left({ }^{\circ} \mathrm{C}\right)$ & 153 & 131 & 184 \\
Gurley (sec) & 640 & 221 & 473 \\
Puncture strength $(\mathrm{g})$ & 550 & 640 & 391 \\
\hline
\end{tabular}

\footnotetext{
${ }^{1}$ Porosity of PE substrate (air-permeability-determining layer).
} 
${ }^{2}$ Porosity of composite membrane calculated from the thickness and porosity of each layer.

Compared to the Celgard 2320 film, the base PE substrate has a higher thickness and a lower porosity, and thus a higher puncture strength and a lower air permeability (i.e., a higher Gurley number). The MDT of the PE substrate was also lower than that of the commercial Celgard 2320 film due to its single-material component.

The PES/PE/PES nanocomposite membrane was fabricated by electrospinning PES onto both sides of the PE substrate treated with chromic acid for $240 \mathrm{~s}$, and the PES nanofibrous layer was electrospun at a flow rate of $60 \mu \mathrm{L} / \mathrm{min}$. The thickness of each PES nanofibrous layer was 9 $\pm 1 \mu \mathrm{m}$, and the total thickness of the composite membrane was $43 \pm 2 \mu \mathrm{m}$. Compared to the original PE substrate, the composite membrane has an overall higher porosity due to the introduction of the electrospun PES nanofibrous layer (porosity 68\%). However, the porosity of the air-permeability-determining layer (i.e., the middle treated PE substrate layer) was not changed, and therefore the Gurley number was kept the same. The puncture strength of the composite membrane was slightly lower than that of the original PE substrate, which probably resulted from mechanical degradation by the acid etching. The SDT of the composite membrane maintained the same as that of the original PE substrate; however, the MDT was significantly increased to $221^{\circ} \mathrm{C}$ by introduction of the PES nanofibrous layer. The safety margin of the PES/PE/PES nanocomposite separator was thus much broadened than that of the original PE separator. In comparison to the commercial Celgard 2320 film, the new PES/PE/PES nanocomposite membrane had a lower SD temperature and higher MD temperature and therefore 
provided a greater safety margin. Cell performance using the composite membrane has not been tested at the current stage, but it is believed that the result would be considerably close to that using the base PE substrate, as the major properties of the two separators except the thermal property are almost the same.

\section{Conclusions}

The commercial polyethylene LIB separator film has a low MDT, which limits its wide application in HEVs and EVs. To enhance the MDT, polyethersulfone, a polymer with a higher thermal resistance, was electrospun onto the base PE substrate on each side to make a nanocomposite separator. Due to the chemically inert nature of the PE substrate and its weak bonding to the electrospun PES membrane, a chemical etching method with chromic acid treatment to the PE substrate was conducted. The surface topology measurement with AFM showed that with longer acid-treatment time, the surface roughness was increased. FTIR spectroscopy showed that functional polar groups such as $\mathrm{C}=\mathrm{O}$ and $\mathrm{C}-\mathrm{O}$ were introduced onto the PE substrate, leading to an increase in surface tension. The water contact angle on the surface of the PE substrate decreased with the acid-treatment time, due to the increased surface energy and roughness. The PE substrate treated with chromic acid for 240 seconds exhibited a 10 -fold increase of adhesion to the electrospun PES membrane when compared with the untreated one. In another aspect, the morphology of the electrospun PES membrane was also demonstrated to have a great impact on the adhesion. "Wet" nanofibrous layers with solution drippings were electrospun at high flow rates, such as $60 \mu \mathrm{L} / \mathrm{min}$ and $80 \mu \mathrm{L} / \mathrm{min}$, and they could be shown to have better bonding to the PE substrate. Compared to the nanofiber-dominating electrospun 
membrane produced at a flow rate of $20 \mu \mathrm{L} / \mathrm{min}$, they showed $\sim 5$-fold increase in bonding strength to the acid treated PE substrate. Although the porosity of the electrospun PES membrane was decreased with increasing flow rate, it still maintained a high enough porosity $(\sim 68 \%$ at 60 $\mu \mathrm{L} / \mathrm{min}$ ) when compared with that of the base PE substrate. The separator property tests of the PES/PE/PES nanocomposite membrane showed unchanged air permeability and shutdown temperature due to the existence of the PE substrate in the middle layer. The MDT was significantly increased to $221^{\circ} \mathrm{C}$ compared to the original value of $153^{\circ} \mathrm{C}$ of the base $\mathrm{PE}$ substrate, and was higher than the commercial Celgard 2320 film $\left(184^{\circ} \mathrm{C}\right)$. In comparison with other improved approaches, coating the PE separator film with highly porous electrospun PES nanofibrous layer could greatly broaden the safety margin of the separator used in lithium-ion batteries, and still keep other separator properties unchanged.

\section{Acknowledgements}

The financial support for this work was provided by a grant from the SusChEM Program of the National Science Foundation (DMR-1409507) and a grant from ExxonMobil Chemical Company. H.M. would like to acknowledge the Research Fund from the State Key Laboratory of Organic-Inorganic Composites at Beijing University of Chemical Technology (oic-201503004) and the Fundamental Research Funds for the Central Universities (buctrc201501) for partial support of this work.

\section{References}

1. Linden D. (2002) Handbook of Batteries, 3rd ed., McGraw-Hill, New York 
2. Bandhauer T.M., Garimella S., Fuller T.F. J. Electrochem. Soc. (2011); 158: R1-R25.

3. Lisbona D., Snee T. Process Saf. Environ (2011); 89: 434-42.

4. Brodd R.J., Bullock K.R., Leising R.A., Middaugh R.L., Miller J.R., Takeuchi E. J. Electrochem. Soc. (2004); 151: K1-K11.

5. Arora P., Zhang Z.M. Chem. Rev. (2004); 104: 4419-62.

6. Broussely M., Archdale G. J. Power Sources (2004); 136: 386-94.

7. Broussely M. Electron. World (2006); 112: 16-21.

8. Xu K. Chem. Rev. (2004); 104: 4303-417.

9. Croce F., Appetecchi G.B., Persi L., Scrosati B. Nature (1998); 394: 456-8.

10. USABC. (2001) RFPI

11. Abraham K.M. Electrochim. Acta. (1993); 38: 1233-48.

12. Laman F.C., Gee M.A., Denovan J. J. Electrochem. Soc. (1993); 140: L51-L53.

13. Dahn J.R., Fuller E.W., Obrovac M., Vonsacken U. Solid State Ionics (1994); 69: 265-70.

14. www.celgard.com.

15. Chung Y.S., Yoo S.H., Kim C.K. Ind. Eng. Chem. Res. (2009); 48: 4346-51.

16. Yoo S.H., Kim C.K. Ind. Eng. Chem. Res. (2009); 48: 9936-41.

17. Huang Z.M., Zhang Y.Z., Kotaki M., Ramakrishna S. Compos. Sci. Technol. (2003); 63: 2223-53.

18. Zong X.H., Kim K., Fang D.F., Ran S.F., Hsiao B.S., Chu B. Polymer (2002); 43: 4403-12.

19. Choi S.S., Lee Y.S., Joo C.W., Lee S.G., Park J.K., Han K.S. Electrochim. Acta. (2004); 50 : $339-43$.

20. Gopalan A.I., Santhosh P., Manesh K.M., Nho J.H., Kim S.H., Hwang C.G., Lee K.P. J. Membrane Sci. (2008); 325: 683-90. 
21. http://www.matweb.com.

22. http://www.rtpcompany.com/info/data/1400/RTP1400AG-210.htm.

23. David E., Lazar A., Armeanu A. J. Mater. Process Tech. (2004); 157: 284-9.

24.Ueda M., Kostov K.G., Beloto A.F., Leite N.F., Grigorov K.G. Surf. Coat. Tech. (2004); 186: 295-8.

25. Encinas N., Abenojar J., Martinez M.A. Int. J. Adhes. Adhes. (2012); 33: 1-6.

26. Henry C., Minier J.P., Lefevre G. Langmuir (2012); 28: 438-52.

27. Fonseca C., Perena J.M., Fatou J.G., Bello A. J. Mater. Sci. (1985); 20: 3283-8.

28. Bag DS, Kumar VP, Maiti S. Die Angewandte Makromolekulare Chemie (1997); 249: 33-46.

29. Kuvaldina E.V., Shikova T.G. Smirnov S.A., Rybkin V.V. High Energy Chem. (2007); 41: 284-7.

30. Favaro S.L., Rubira A.F., Muniz E.C., Radovanovic E. Polym. Degrad. Stab. (2007); 92: 1219-26.

31. Briggs D. J. Mater. Sci. (1976); 11: 1270-7.

32. Sheng E., Sutherland I., Brewis D.M., Heath R.J., Bradley R.H. J. Mater. Chem. (1994); 4: 487-90.

33. Mathieson I., Bradley R.H. Int. J. Adhes. Adhes. (1995); 16: 29-31.

34. Tang Z.H., Qiu C.Q., McCutcheon J.R., Yoon K., Ma H.Y., Fang D.F., Lee E., Kopp C., Hsiao B.S., Chu B. J. Polym. Sci. Part B: Polym. Phys. (2009); 47: 2288-300.

35. Yoon K., Hsiao B.S., Chu B. Polymer (2009); 50: 2893-9.

36. Liu Y., Ma H.Y., Liu B., Hsiao B.S., Chu B. J. Plast. Film. Sheet (2015); 31(4): 379-400.

37. Fjuii T.M.T. (1998). U.S. Patent 5,759,678

38. Gulmine J.V., Janissek P.R., Heise H.M., Akcelrud L. Polym. Test (2002); 21: 557-63. 
39. Rasko J. Catal. Lett. (1998); 56: 11-5.

40. Lafuma A., Quere D. Nat. Mater. (2003); 2: 457-60. 


\section{Improvement of Meltdown Temperature of Lithium-Ion Battery Separator using Electrospun Polyethersulfone Membranes}

Yang Liu ${ }^{1}$, Hongyang $\mathrm{Ma}^{1,2, *}$, Benjamin S. Hsiao ${ }^{1, *}$, Benjamin $\mathrm{Chu}^{1}$, Andy H. Tsou ${ }^{3}$

${ }^{1}$ Department of Chemistry, Stony Brook University, Stony Brook, NY 11794, USA

${ }^{2}$ State Key Laboratory of Organic-Inorganic Composites, Beijing University of Chemical

Technology, Beijing 100029, China

${ }^{3}$ Global Chemical Research, ExxonMobil Chemical Company, 5200 Bayway Drive, Baytown, TX 77520, USA

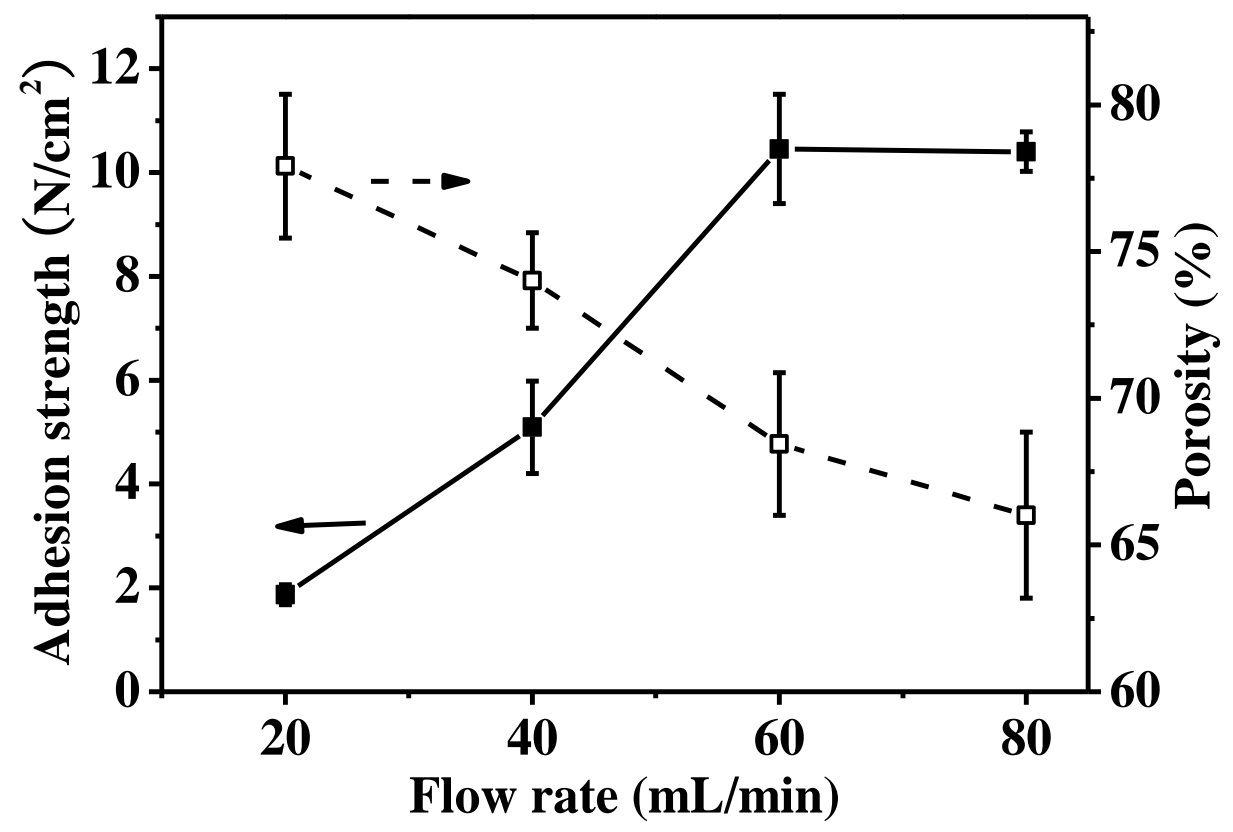

\section{Corresponding authors:}

Phone: (631)229-6899 (H.M.); (631)632-7793 (B.S.H). Fax: (631)632-6518

E-mails: mahy@ mail.buct.edu.cn (H.M.); benjamin.hsiao@ stonybrook.edu (B.S.H.) 